\title{
EFEITOS DA CORRENTE MICROGALVÂNICA E DA MICRODERMOABRASÃO PARA TRATAMENTO DE ESTRIAS ATRÓFICAS: REVISÃO DE LITERATURA
}

\author{
EFFECTS OF CURRENT MICROGALVÂNICA AND MICRODERMABRASION \\ FOR STRETCH MARKS TREATMENT: LITERATURE REVIEW
}

Geisenely Vieira dos Santos Ferreira (FERREIRA, G.V.S) Especialista em Biomedicina Estética. Docente da Faculdade Evangélica de Ceres-GO.

E-mail: geisenely@gmail.com

\section{Endereço para correspondência:}

Rua 02, Qd. 01, L04, Residencial Terezinha Braga Anápolis - GO. Brasil. CEP: 75144-850

Fone: (62) 99103-8571

E-mail: geisenely@gmail.com

\section{RESUMO}

INTRODUÇÃO: A estria é uma atrofia tegumentar adquirida que modifica fibras colágenas, fibras elásticas, substância fundamental amorfa e fibroblastos. Os recursos definidos para esta pesquisa foram a microgalvanopuntura e a microdermoabrasão. OBJETIVOS: Analisar os efeitos terapêuticos da microgalvanopuntura e da microdermoabrasão no tratamento de estrias. METODOLOGIA: Na pesquisa fez-se uso de artigos publicados, nomeadamente banco de dados eletrônicos, sites de pesquisa e livros. Os artigos foram pesquisados no idioma português. Durante a coleta dos dados foram encontrados150 artigos e alguns capítulos de livros relacionados ao tema proposto. Destes, apenas 19 se enquadravam nos critérios de inclusão do estudo. Os descritores utilizados foram: Tratamentos estéticos, microgalvanopuntura, microdermoabrasão, Estrias. RESULTADOS E DISCUSSÃO: A microdermoabrasão remove as células envelhecidas e estimula a produção de células jovens e colágeno. A lesão provocada pela microgalvanopuntura leva a produção de diversas enzimas responsáveis pelo processo inflamatório, além de células como os fibroblastos, promovendo assim a regeneração tecidual e melhorando o aspecto da pele. CONCLUSÃo: O estudo mostrou que os procedimentos abordados obtiveram resultados positivos na melhora do estado do tecido estriado. Assim, há também a necessidade de novas pesquisas, pois a literatura consultada não deixa claro qual metodo é mais eficiente devido à pouca quantidade de publicação, especialmente focada nas duas técnicas apresentadas em conjunto. É um problema cada vez mais comum que afeta a autoestima da maioria das mulheres.

Palavras-chave: Tratamentos estéticos. Microgalvanopuntura. Microdermoabrasão. Estrias 


\begin{abstract}
INTRODUCTION: The ridge is an acquired cutaneous atrophy that modifies collagen fibers, elastic fibers, amorphous ground substance and fibroblasts. The feature set for this survey were Microgalvanopuntura and microdermabrasion. OBJECTIVES: To evaluate the therapeutic effects of Microgalvanopuntura and microdermabrasion in the treatment of stretch marks. METHODOLOGY: The research covered published articles, using electronic databases, research sites and books. The articles were searched in the Portuguese language. During data collection, 150 articles were found and some book chapters related to the proposed theme, of which only 19 met the study's inclusion criteria. The descriptors used were: Aesthetic treatments, microgalvanopuncture, microdermabrasion, Stretch marks. RESULTS AND DISCUSSION: The microdermabrasion removes aged cells and stimulates production of collagen and young cells. The injury caused by Microgalvanopuntura leads to the production of various enzymes responsible for the inflammatory process, in addition to cells such as fibroblasts, thus promoting tissue regeneration and improving the appearance of the skin. Conclusion: The study showed that the approached procedures obtained positive results in improving the state of the striated tissue. Thus, there is also a need for further research, since the literature consulted does not make it clear which method is more efficient due to the small amount of publication, especially focused on the two techniques presented together. It is an increasingly common problem that affects the self-esteem of most women.
\end{abstract}

Keywords: Aesthetic Treatments. Microgalvanopuncture. Microdermabrasion. Stretch Marks 


\section{INTRODUÇÃO}

A estria é uma afecção estética que afeta mulheres e homens, porém tem prevalência nas mulheres de diferentes faixas etárias, principalmente a partir da adolescência. Com efeito, a estria acarreta um comprometimento físico e emocional, diminuição da autoestima, em razão do padrão estético e corporal requerido pela sociedade atual, nomeadamente a supervalorização do corpo ideal e veneração à perfeição estética (MACHADO, 2016).

As estrias surgem em razão de alterações nas fibras de colágeno e elastina, que são responsáveis pela sustentação e elasticidade da pele; estão localizadas na derme, camada mais profunda da pele (REZENDE; PINHEIRO; MENDONÇA, 2016). Podem ocorrer por vários fatores e situações, sendo comum o seu aparecimento durante a puberdade em decorrência do crescimento acelerado, aumento de peso repentino, gravidez, alterações hormonais, bem como o uso de alguns medicamentos. São sintomas iniciais o prurido local (coceira) e a pele levemente rosada (GUIRRO; GUIRRO, 2004; BORGES, 2010).

Com efeito, constituem lesões lineares não desejadas que normalmente obedecem às linhas de clivagem da pele e a sua extensão pode variar, sendo caracterizadas pela redução dos elementos celulares (GUIMARAES et al, 2019). Ademais, surgem principalmente em regiões de maior alteração tecidual, com acúmulo de gordura. Geralmente em coxas, glúteos, seios e no abdômen. No início, as lesões são avermelhadas ou róseas, devido o processo inflamatório presente; posteriormente, elas evoluem para uma tonalidade esbranquiçada, tornando-se mais largas e pálidas sendo denominadas de estrias albas (SILVA; FECK, 2018).

Vários autores relatam não existir um tratamento eficaz que as elimine por completo. No entanto, estudos comprovam a eficácia de alguns recursos amplamente utilizados, que oferecem mudanças morfológicas, histoquímicos e funcionais do aspecto e da coloração, largura e espessura das estrias, resultando na melhora da autoestima e bem-estar da paciente (REZENDE; PINHEIRO; MENDONÇA, 2016).

Existem diversos tratamentos na área da estética disponíveis e capazes de atenuar o aspecto das estrias. Por exemplo, a microgalvanopuntura e a microdermoabrasão, técnicas escolhidas para o presente estudo. Portanto, é muito importante que pesquisas e trabalhos sejam concretizados, de modo a confirmar ou não a eficiência dos tratamentos propostos (SILVA et al, 2016). 
No presente estudo, tem-se por objetivo analisar, via levantamento bibliográfico, os efeitos do tratamento estético o qual faz uso da microgalvanopuntura e da microdermoabrasão em estrias atróficas.

\section{METODOLOGIA}

Esta pesquisa consistiu em uma revisão bibliográfica, na qual foram examinados livros e artigos científicos publicados em periódicos indexados nas bases de dados tais como SCIELO, BIREME e LILACS. Com o objetivo de alcançar uma melhor compreensão do tema e apresentação de uma proposta terapêutica eficaz no tratamento das estrias, restringiu-se a dois recursos, a saber: a microgalvanopuntura e a microdermoabrasão.

Os artigos foram pesquisados no idioma português, cujos descritores e/ou palavras- chave foram: Tratamentos estéticos, Microgalvanopuntura, Microdermoabrasão, Estrias. Uma vez detectados, esses artigos foram então analisados à luz dos relatos de casos que utilizaram a microgalvanopuntura e a microdermoabrasão como métodos de tratamento das estrias. Foram incorporados a esses artigos, livros referentes à área da fisioterapia dermatofuncional que também tratavam do assunto.

\section{RESULTADOS E DISCUSSÃO}

Cabe ressaltar que foram encontrados 150 estudos relativos aos descritores utilizados. Todavia, apenas 19 destes se enquadravam nos critérios supracitados. A terapêutica das estrias e os efeitos que cada técnica é capaz de proporcionar dependem de vários fatores particulares de cada indivíduo, a saber: a raça e idade (são determinantes), além do número de sessões e recursos utilizados para este fim. São várias as técnicas existentes no mercado capazes de diminuir a produção de fibrose e estimular a produção de células jovens, devolvendo a pele um aspecto mais saudável (MACHADO, 2016).

Dentre as técnicas mais empregadas está a microdermoabrasão, constituindo-se de um método seguro e capaz de promover a renovação das camadas mais superficiais da pele, sua classificação se dá de acordo com a camada atingida (LUZ; OLIVEIRA, 2017). A abrasão pode se dar apenas em nível de epiderme, assim como em camadas mais profundas como a derme. Porém, a ação fisioterapêutica está restrita ao primeiro nível, visto que os outros 
envolvem o uso de medicamentos com ação analgésica (BOING; NITSCH; NASCIMENTO, 2017).

A microdermoabrasão remove as células envelhecidas e estimula a produção de células jovens e novo colágeno, melhorando o aspecto da pele (BORGES, 2010). Entretanto, uma pesquisa evidenciou os efeitos da técnica em uma única aplicação, através de análise histopatológica. Não houve alteração significativa na espessura da pele ou na organização da camada córnea (OLIVEIRA, 2016). Porém, um dos fatores determinantes para o sucesso do tratamento das estrias, a despeito da técnica escolhida, inclui o número total de sessões que deve ser calculado conforme as particularidades de cada paciente (BOING; NITSCH: NASCIMENTO 2017).

Apesar de ser um método eficaz no tratamento das estrias, a maioria dos profissionais faz uso dos peelings mecânicos (peeling de cristal ou diamante) para minimizar as barreiras de penetração de substâncias como ácidos (peelings químicos), ação esta que se torna difícil quando a pele se encontra intacta, obtendo assim melhores resultados (KEDE; SABATOVICH, 2015).

Além da microdermoabrasão, vários estudos citam a microgalvanopuntura como uma das técnicas mais empregadas no tratamento das estrias, além de apontar a sua eficácia nas intervenções. $\mathrm{O}$ aparelho utilizado consiste em uma corrente contínua filtrada constante composto de dois eletrodos: um passivo, tipo placa, utilizado com uma esponja umedecida fixada em um ponto próximo à região tratada; e um ativo, constituído por uma fina agulha sustentada por uma caneta. A agulha é introduzida entre as camadas da epiderme. Dado que não atinge a derme, não há sangramento (PESSARELLO et al, 2020).

A lesão provocada pela punturação gera uma inflamação local, com hiperemia e edema localizados, que levam a produção de diversas enzimas responsáveis pelo processo inflamatório e da criação de células jovens, a exemplo dos fibroblastos, e, desta forma o tecido é então regenerado (SILVA; FECK, 2018).

Em um estudo de caso de uma paciente do sexo feminino, de cor branca, a corrente microamperada foi empregada nas estrias na região de quadril e coxas durante 20 sessões, 1 vez por semana. Também aplicou-se punturação com intensidade de 70 a $100 \mu \mathrm{A}$ modulada, respeitando-se a sensibilidade da voluntária. A microscopia da epiderme constatou o aparecimento de uma quantidade significativa de fibras colágenas e fibroblastos, ao passo que houve também uma maior vascularização da área, mostrando que o tratamento promoveu reparação e melhora do aspecto visual (WHITE, 2017). 
Já em um estudo realizado com seis pacientes (todas de cor branca), foi utilizada também a microgalvanopuntura durante 10 sessões. Houve variações nas aplicações de cada candidata, e o tempo entre uma sessão e outra foi de aproximadamente sete dias; houve punturação em todos os casos. O questionário de satisfação aplicado a elas bem como o registro fotográfico permitiram mostrar melhora em apenas duas das seis pacientes tratadas. Nas demais o aspecto manteve-se inalterado, havendo piora do quadro em algumas delas (MONDO; ROSAS, 2004).

Vale ressaltar que cada organismo reage de maneira diferente, assim como ocorre no tratamento de outras doenças. Por esta razão, o número de sessões é estabelecido consoante as individualidades de cada um. Não obstante, uma estria deve receber várias aplicações, além de um tratamento total longo para resultados satisfatórios (MONDO; ROSAS, 2004). Exemplo de tais particularidades são as peles escuras que têm capacidade regenerativa maior do que peles brancas (KEDE; SABATOVICH, 2015).

Objetivando verificar a aplicação da corrente galvânica adaptada a uma máquina de tatuar em uma paciente de cor branca, foram tratadas durante 7 sessões, 1 a cada semana, três estrias; na primeira, foi aplicada a corrente de forma tradicional; na segunda, a aplicação foi realizada com a máquina de tatuar associada à corrente e a última somente a máquina. Observou-se que o uso da máquina associada à corrente galvânica promoveu uma resposta inflamatória mais prolongada e com um desconforto menor ao paciente (MACHADO, 2016).

Segundo Borges (2010), quanto mais prolongado for o processo inflamatório, melhor o resultado. Porém, dever-se-ia atentar ao tempo decorrente entre uma aplicação e outra, sempre respeitando o tempo estimado para regeneração tecidual, que é de 2 a 7 dias para que o processo inflamatório não se torne crônico.

Outra pesquisa comparou o efeito da punturação feita com o aparelho STRIAT (IBRAMED) ligado e desligado em uma paciente de cor "morena clara" durante 10 sessões, 1 a cada semana. Realizou-se aplicação no hemicorpo direito com o aparelho ligado e no esquerdo desligado, ambas utilizando a técnica de punturação. Na aplicação com o aparelho ligado, a intensidade foi de $100 \mu \mathrm{A}$. Neste caso, houve melhora visual das estrias e a paciente se mostrou satisfeita nos dois casos; porém, mais evidenciada no hemicorpo direito, tratado com aparelho ligado, a resposta não se mostrou significativa na parte tratada uma vez desligado o aparelho (GALDINO; DIAS; CAIXETA, 2010).

Estes mesmos resultados também foram descritos em outro estudo, desta vez, via análise microscópica da pele. A amostra contava 12 voluntárias de cor branca tratadas durante 
4 sessões, sendo 1 a cada semana completando 1 mês. A intensidade e a forma de aplicação foram as mesmas do estudo anterior (CONSULIM, 2008).

Em relação à intensidade utilizada, os valores de microamperagem variam entre os autores. Alguns utilizam a faixa de 70 a 100 microampères, não ultrapassando os 400 microampères (BORGES, 2010); já outros empregam valores que variam de 150 a 300 microampères, de acordo com o limiar sensitivo de cada indivíduo (AGNE, 2011). Considerase também que em peles mais finas e sensíveis podem ser utilizadas intensidades mais baixas do que em peles mais resistentes (BORGES, 2010).

Em novo estudo comparativo entre a utilização da corrente associada ao trauma mecânico (aparelho ligado) e somente o trauma (aparelho desligado) em uma amostra de 10 pacientes, ora aplicando trauma e corrente ora apenas trauma, demonstrou-se que o grau de satisfação geral foi bom, e, através de uma enquete, sugeriu-se que o tratamento apenas com o trauma mecânico apresenta resultados estéticos melhores do que associado à microcorrente (WHITE, 2017).

Com a proposta de análise dos efeitos da microgalvanopuntura com as chamadas estrias albas, além da verificação do estresse oxidativo e perfil lipídico através da concentração plasmática de algumas substâncias, foram utilizadas trinta e duas mulheres que possuíam tipos de pele de I a V. Ao todo foram 10 sessões, 1 por semana, em que se fez uso da técnica de punturação. Constatou-se que o processo inflamatório produzido pela punturação está restrito tão-somente ao local da aplicação não produzindo, por conseguinte, respostas sistêmicas; diminuindo-se assim o estresse oxidativo e a consequente melhora no perfil lipídico (BITENCOURT, 2007).

Em um estudo comparativo foram utilizadas a microcorrente e a acupuntura no tratamento de estrias pardas em região de flancos em uma paciente do sexo feminino durante 4 sessões. Foi utilizada no flanco direito, a acupuntura associada à eletroestimulação, aplicando as agulhas no trajeto da estria durante 20 minutos e aplicação de Moxa durante 2 minutos; já em flanco esquerdo, aplicou-se corrente microamperada com intensidade suportada pela paciente. Ao final do estudo, observou-se que houve melhora significativa nos dois casos, porém, conforme relatou a própria paciente, a acupuntura apresentou resultados mais satisfatórios, apesar de ser mais dolorosa e demorada (BORGES; SCORZA, 2016).

Outro estudo de caráter também comparativo propôs verificar os efeitos da eletroterapia. Nesse caso, fez-se uso da microgalvanopuntura através da técnica de punturação, juntamente com a vitamina $\mathrm{C}$ e do ácido retinóico na atenuação das estrias. $\mathrm{A}$ amostra contava 6 mulheres, de cor branca com estrias na região de culotes; estas foram 
aleatoriamente separadas em dois grupos: grupo A, tratado com eletroterapia e vitamina $\mathrm{C}$; e grupo B, tratado apenas com o mencionado ácido. Cada grupo possuía 3 participantes. Foram realizadas 5 sessões 1 a cada semana. Por meio de registro fotográfico, observou-se a melhora do aspecto e um bom nível de satisfação no grupo A, o que não ocorreu no grupo B (OLIVEIRA, 2016).

Apesar de ser um tratamento eficaz, não é possível obter a cura total das estrias (KEDE; SABATOVICH, 2015). Esse fato faz com que muitas pessoas desistam do tratamento. Além disso, as causas mais frequentes que levam ao encerramento do tratamento são as complicações geradas, a dor causada pela aplicação e o insucesso da terapia para aqueles que não cumprem as recomendações durante o tratamento (SILVA et al, 2017).

Tais indicações, quando seguidas, são capazes de tornar o tratamento mais eficaz, a saber: não expor a área tratada ao sol pelo risco de acentuar as marcas e ocasionar manchas, não fazer uso de antinflamatórios ou qualquer recurso que atenue o processo inflamatório e seguir corretamente a frequência das sessões (AGNE, 2011). 


\section{CONCLUSÃO}

O estudo demostrou que os procedimentos abordados obtiveram resultados positivos no estado do tecido estriado. Porém, deve-se levar em consideração que essa é uma disfunção multifatorial, e como tal, os pacientes acometidos pela disfunção devem buscar tratamentos logo no início do aparecimento das primeiras estrias, pois, como evidenciado ao longo da pesquisa, nenhuma técnica é capaz de promover a cura definitiva da estria, fato que deve ser esclarecido a todos que se submetem a tais procedimentos estéticos.

Tendo em vista os aspectos observados, faz-se necessário que sejam realizadas mais e mais pesquisas, uma vez que a literatura consultada não deixa claro qual o método mais eficaz, seja pela baixa quantidade de publicação especialmente voltada às duas técnicas salientadas e conjugadas para o tratamento das estrias. E, obviamente, também pelo fato de ser um problema cada vez mais frequente, que afeta consideravelmente a estética corporal e a autoestima de grande parte das mulheres. 


\section{REFERÊNCIAS}

AGNE, J. E. Eu sei eletroterapia. 2a ed. São Paulo: Andreoli, 2011.

BITENCOURT, S. Tratamento de estrias albas com galvanopuntura: benéfico para a estética, estresse oxidativo e perfil lipídico. 36f. 2007. Dissertação (Mestrado em Biologia Celular e Molecular) - PUC - Rio Grande do Sul, Porto Alegre, 2007. Disponível em: < http://tede2.pucrs.br/tede2/handle/tede/5526\%3E.>. Acesso em: 12 jul. 2019.

BOING, G.; NITSCH, G. NASCIMENTO, B.K Estudo comparativo da utilização da endermologia associado à pipeta de vidro e pipeta de vidro com fator de crescimento para o tratamento de estrias atróficas. 22f. 2017. TCC (Graduação em Cosmetologia e Estética) -

UNISUL, Santa Catarina, 2017. Disponível em: <https://riuni.unisul.br/handle/12345/2190>. Acesso em: 12 jul. 2019.

BORGES, F. Dermato - Funcional: Modalidades terapêuticas nas disfunções estéticas. São Paulo: Ed. Phorte, 2010.

BORGES, F. S.; SCORZA, F.A. Terapêutica em estética: conceitos e técnicas. 1 ed. São Paulo: Phorte, 2016.

GALDINO, A. P. G; DIAS, K. M; CAIXETA, A. Análise comparativa do efeito da corrente microgalvânica: estudo de caso no tratamento de estrias atróficas. Revista Saúde CESUC. Goiás, ano I, n.1, p. 1-10, 2010. Disponível em: <https://www.cesuc.br/Cesuc,INF,TVRFMQ.rb>. Acesso em: 28 jun.2020.

GUIMARÃES, D.M.; LIMA, F.O.; CARVALHO, K.A.L.; SOUSA, K.A.; FERREIRA, K.S.; PEREIRA, M.I.M.; NEVES, N.S.; RESENDE, V.A.S.; BOSI, P.L Uso da micropigmentação como método de camuflagem para cicatriz de estrias. Fisioterapia Brasil. São Paulo, v. 20, n. 3, p. 442-447, 2019. Disponível em: <https://portalatlanticaeditora.com.br/index.php/fisioterapiabrasil>. Acesso em: 28 jun. 2020.

GUIRRO, E.; GUIRRO, R. Fisioterapia Dermato-Funcional: Fundamentos recursos e patologias. 3. ed. rev. e ampl. São Paulo: Editora Manole, 2004.

KEDE, V. P. M.; SABATOVICH, O. Dermatologia Estética. 3 ed. São Paulo: Editora Atheneu, 2015.

LUZ, M. R.; OLIVEIRA, S. P. Tratamento com microagulhamento em estrias atróficas: galvanopuntura x dermaroler. 21f. 2017. Trabalho de conclusão de curso (Tecnologia em Estética e Cosmética) - Universidade Tuiuti do Paraná, Paraná, 2017. Disponível em: $<$ https://portalatlanticaeditora.com.br/index.php/fisioterapiabrasil>. Acesso em: 20 jun. 2019. 
MACHADO, D.C.D. Utilização da galvanoterapia na regeneração de estrias atróficas: um estudo piloto sobre a satisfação com o tratamento. Fisioterapia Brasil. São Paulo, v. 15, n. 3, p. 210-216, 2016.2 Disponível em:<https://portalatlanticaeditora.com.br/index.php/fisioterapiabrasil $>$. Acesso em: 20 jun. 2019.

MONDO, P.K.S.; ROSAS, R.F. Efeitos da corrente galvânica no tratamento das estrias atróficas. 15f. 2004. TCC (Graduação em Fisioterapia) - Universidade do Sul de Santa Catarina, Santa Catarina, 2004. Disponível em: <http://www.portalatlanticaeditora.com.br/index.php/fisioterapiabrasil/article/view/1613>. Acesso em: 15 jun. 2019.

OLIVEIRA, I. C. Análise dos efeitos provocados pela utilização da vacuoterapia associada à aplicação da vitamina c nas estrias brancas: um relato de caso. 45f. 2016 . TCC (Graduação em Fisioterapia) - Centro Universitário de Formiga, Minas Gerais, 2016. Disponível em: <https://bibliotecadigital.uniformg.edu.br:21015/xmlui/handle/123456789/428\#: :text=O\%20 estudo\%20teve \%20como\%20objetivo,medidas\%20de\%20comprimento\%20das $\% 20$ estria>. Acesso em: 22 jun. 2019.

PESSARELlO, J.P.; ALVES, J.S.; MARUNO, M.; PETERSEN, B.C. Resultados dermatológicos e padronização do procedimento estético de microdermoabrasão: revisão integrativa da literatura. Revista Inspirar Movimento \& Saúde. Paraná, v. 20, n. 1, p. 1-19, 2020. Disponível em: <https://www.inspirar.com.br/revista-inspirar/>. Acesso em: 20 jun. 2020.

REZENDE, P.P.; PINHEIRO, N.M.; MENDONÇA, A.C. Recursos terapêuticos utilizados no tratamento de estrias de distensão: uma revisão sistemática. Jornal de ciências biomédicas e saúde. Minas Gerais, v. 1, n. 3, p. 3, 2016. Disponível em: <http://publicacoes.facthus.edu.br/index.php/saude/index>. Acesso em: 19 jul. 2019.

SILVA, C.L.C.; FONTES, C.F.; LIMA, G.F.M.; BATISTA, H.N.; SILVA, R.K.R.; FRANCO, I.M.O. Comparativo entre galvanopuntura e microagulhamento, SE. In: SEMANA DE PESQUISA DA UNIVERSIDADE TIRADENTES, 18, 2016, Aracaju. Anais [...]. Sergipe: UNIVERSIDADE TIRADENTES, 2016. p. 1-3. Disponível em: $<$ https://eventos.set.edu.br/index.php/sempesq/article/view/3711>. Acesso em: 13 jul. 2019.

SILVA, J.P.; FECK, S.G. O uso da corrente galvânica nas estrias atróficas: uma revisão bibliográfica. Conversas Interdisciplinares. Rio Grande do Sul, v. 15, n. 1, p. 108-120, 2018. Disponível em: <http://www.periodicos.ulbra.br/index.php/ci>. Acesso em: 15 jul. 2019. 
SILVA, M.L.; SILVA, V.G.; ROSA, P.V. Análise dos efeitos da utilização da microgalvanopuntura e do microagulhamento no tratamento das estrias atróficas. Revista Biomotriz. Rio Grande do Sul, v. 11, n. 1, p. 49-63, 2017. Disponível em: $<$ https://revistaeletronica.unicruz.edu.br/index.php/BIOMOTRIZ/index >. Acesso em: 12 jul. 2019.

WHITE, P. A. S. et al. Efeitos da galvanopuntura no tratamento das estrias atróficas. Fisioterapia Brasil. São Paulo, v. 9, n. 1, p. 53- 58, 2017. Disponível em: <https://portalatlanticaeditora.com.br/index.php/fisioterapiabrasil>. Acesso em: 15 jul. 2019. 